\title{
Novel Glycolipoproteins from Ginseng
}

\author{
Mi Kyung Pyo ${ }^{1 \#}$, Sun-Hye Choi ${ }^{1 \#}$, Sung Hee Hwang ${ }^{1 \#}$, Tae-Joon Shin ${ }^{1}$, Byung-Hwan Lee ${ }^{1}$, Sang- \\ Mok Lee ${ }^{1}$, Yoong-Ho Lim², Dong-Hyun $\mathrm{Kim}^{3}$, and Seung-Yeol Nah ${ }^{1^{*}}$ \\ ${ }^{1}$ Ginsentology Research Laboratory and Department of Physiology, College of Veterinary Medicine and Bio/Molecular \\ Informatics Center, Konkuk University, Seoul 143-701, Korea \\ ${ }^{2}$ Department of Bioscience and Biotechnology, Konkuk University, Seoul 143-701, Korea \\ ${ }^{3}$ College of Pharmacy, Kyung Hee University, Seoul 130-701, Korea
}

Ginseng has been used as a general tonic agent to invigorate human body. In the present study, we isolated novel glycolipoproteins from ginseng that activate $\mathrm{Ca}^{2+}$-activated $\mathrm{Cl}^{-}$channel $(\mathrm{CaCC})$ in Xenopus oocytes and transiently increase intracellular free $\mathrm{Ca}^{2+}$ concentration $\left(\left[\mathrm{Ca}^{2+}\right]_{\mathrm{i}}\right)$ in mouse Ehrlich ascites tumor cells. We named the active ingredients as gintonin. Gintonin exists in at least six different forms. The native molecular weight of gintonin is about $67 \mathrm{kDa}$ but its apparent molecular weight is about $13 \mathrm{kDa}$, indicating that gintonin might be a pentamer. Gintonin is rich in hydrophobic amino acids. Its main carbohydrates are glucose and glucosamine. Its lipid components are linoleic, palmitic, oleic, and stearic acids. Gintonin actions were blocked by U73122, a phospholipase C inhibitor, 2-aminoethxydiphenyl borate, an inositol 1,4,5-trisphosphate receptor antagonist, or bis (o-aminophenoxy) ethane-N,N,N0,N0-tetracetic acid acetoxymethyl ester, a membrane permeable $\mathrm{Ca}^{2+}$ chelator. In the present study, we for the first time isolated novel gintonin and showed the signaling pathways on gintonin-mediated CaCC activations and transient increase of $\left[\mathrm{Ca}^{2+}\right]_{\mathrm{i}}$. Since $\left[\mathrm{Ca}^{2+}\right]_{\mathrm{i}}$ as a second messenger plays a pivotal role in the regulation of diverse $\mathrm{Ca}^{2+}$-dependent intracellular signal pathways, gintonin-mediated regulations of $\left[\mathrm{Ca}^{2+}\right]_{\mathrm{i}}$ might contribute to biological actions of ginseng.

Keywords: Panax ginseng, Korean red ginseng, Glycolipoproteins, Gintonin, $\left[\mathrm{Ca}^{2+}\right]_{\mathrm{i}}$ mobilization

\section{INTRODUCTION}

Ginseng has been used as a general tonic or an adaptogen to promote longevity and enhance bodily functions against stress, fatigue, diseases, cancer and diabetes mellitus [1]. Ginseng is one of the most widely used and precious herbal medicines consumed in around the world [1]. Ginsenosides (also called ginseng saponins) were first isolated from ginseng in the beginning of 1960s and well characterized [2,3]. Ginsenosides have been used and reported as the representative ingredients in most ginseng-related biochemical studies [1]. Since the content of ginsenoside within ginseng is low, ginsenoside isolation from ginseng is complicated, and as a result pure ginsenosides are expensive, thus we and others have used crude ginseng total saponin fraction (CGSF) that has been prepared from butanol extraction of ginseng root to explain various in vitro and in vivo physiological or pharmacological actions of ginseng [4-10].

Regarding to intracellular $\mathrm{Ca}^{2+}$-related actions of CGSF,

cc This is an Open Access article distributed under the terms of the Creative Commons Attribution Non-Commercial License (http://creativecommons.org/licenses/by-nc/3.0/) which permits unrestricted non-commercial use, distribution, and reproduction in any medium, provided the original work is properly cited.
Received 8 Nov. 2010, Revised 9 Dec. 2010, Accepted 9 Dec. 2010

*Corresponding author

E-mail: synah@konkuk.ac.kr

Tel: +82-2-450-4154, Fax: +82-2-450-2809

\#Authors contributed equally to this work. 
we have shown that CGSF achieves its action through well-known membrane signaling pathways such as guanosine triphosphate (GTP)-binding protein-coupled receptors. For example, Choi et al. [5] demonstrated that CGSF treatment activated endogenous $\mathrm{Ca}^{2+}$-activated $\mathrm{Cl}^{-}$channel $(\mathrm{CaCC})$ through the signaling pathway that activates pertussis toxin-insensitive $\mathrm{G} \alpha_{q^{\prime} 11}$ proteins coupled to phospholipase C (PLC) $\beta$-inositol 1,4,5-trisphosphate $\left(\mathrm{IP}_{3}\right)$ in Xenopus oocytes. Lee et al. [11] also demonstrated that CGSF-mediated $\mathrm{CaCC}$ activation was desensitized through activation of $\mathrm{G}$ protein kinase 2 and $\beta$ - arrestin I in Xenopus oocytes. CGSF treatment induced store-operated $\mathrm{Ca}^{2+}$ entry in Xenopus oocytes [12]. These results indicate that CGSF treatment induces an increase of $\left[\mathrm{Ca}^{2+}\right]_{\mathrm{i}}$ from intracellular $\mathrm{Ca}^{2+}$ stores or from outside the cell and that the elevated $\left[\mathrm{Ca}^{2+}\right]_{\mathrm{i}}$ is coupled to $\mathrm{CaCC}$ activations in Xenopus oocytes [13].

During purification processes for isolating pure ginsenosides from CGSF to identify which ginsenoside(s) are responsible for $\mathrm{CaCC}$ activations, we have obtained evidences that ginsenosides in CGSF are not responsible for $\mathrm{CaCC}$ activations in Xenopus oocytes. In the present study, to further identify and characterize the novel ingredients underlying $\mathrm{CaCC}$ activations in CGSF, we have for the first time, isolated the active ingredients. We found that the active ingredients are a type of glycolipoproteins. We named the gintonin; transient intracellular $\mathrm{Ca}^{2+}$ elevating agents isolated from ginseng. Since $\mathrm{Ca}^{2+}$ is a second messenger and is involved in a variety of cellular functions such as the regulation of contraction, plasticity, secretion, synaptic transmission, and gene expression [14], gintonin-mediated elevation of $\left[\mathrm{Ca}^{2+}\right]_{i}$ may play an important role in the regulation of a variety of $\mathrm{Ca}^{2+}$-dependent intracellular signaling pathways.

\section{MATERIALS AND METHODS}

\section{Materials}

Six-year-old Korea red ginseng (Korea Ginseng Cooperation, Daejeon, Korea) were purchased from local ginseng market and identified by adjunct professor $\mathrm{NJ}$ Kim, College of Pharmacy, Kyung Hee University and the specimen (CVMKU 200607-14) were deposited at the herbarium of the laboratory. American ginseng (Panax quinquefolis) roots were obtained from Hsu's Ginseng Enterprise \& Hsu Ginseng Farm (Wausau, WI, USA). BioLogic DuoFlow ${ }^{\mathrm{TM}}$ chromatography systems were purchased from Bio-Rad (Hercules, CA, USA). Ehrlich ascites tumor (EAT) cells were kindly provided from Riken BRC Cell Bank (Tsukuba, Japan). The prepacked columns (Superdex 75 10/30/300 GL and HiTrap $^{\mathrm{TM}}$ DEAE FF) and media (DEAE Sepharose CL6B) were purchased from GE Healthcare (Uppsala, Sweden). Fura 2-AM was obtained from Molecular Probes (Eugene, OR, USA). Schiff's reagent, tubing cellulose membrane with molecular weight cut off at 13,000 , and other reagents were purchased from SigmaAldrich (St. Louis, MO, USA). Male ICR mice (20-30 g) were obtained from Orient Bio, Inc. (Seongnam, Korea). Ginsenoside $\mathrm{Ra}, \mathrm{Rb}_{1}, \mathrm{Rb}_{2}, \mathrm{Rc}, \mathrm{Rg}_{1}$, and other ginsenosides were purchased from LKT institute (St. Paul, MN, USA).

\section{Preparation of non-saponin fraction from metha- nol and butanol extractions}

Twenty kilograms of 6-year-old Korean red ginseng roots were grinded into small pieces $(>3 \mathrm{~mm})$ and refluxed with $80 \%$ methanol $(\mathrm{MeOH})$ three times for $8 \mathrm{~h}$ at $80^{\circ} \mathrm{C}$ each. The $\mathrm{MeOH}$ extracts $(6.2 \mathrm{~kg})$ concentrated in vacuo was partitioned between $n$-butanol $(n-\mathrm{BuOH})$ and water. $n$-BuOH fraction (908 g), after concentration, was applied to a silica gel column and was eluted with chloroform $\left(\mathrm{CHCl}_{3}\right)$ :MeOH:water $\left(\mathrm{H}_{2} \mathrm{O}\right)=13: 7: 2$. Each fraction was tested on endogenous $\mathrm{CaCC}$ activations in Xenopus oocytes. The only active fraction was further separated through a silica gel column and was eluted with ethyl acetate (EtOAc):ethanol $(\mathrm{EtOH}): \mathrm{H}_{2} \mathrm{O}=1: 3: 0.5$. The active fraction which activates $\mathrm{CaCC}$ was dialyzed at $4{ }^{\circ} \mathrm{C}$ for $8 \mathrm{~h}$ with 1,000 -fold excess distilled water using Spectra/Por dialysis membrane (molecular weight cut off 6,000-8,000) (Spectrum Laboratories Inc., Rancho Dominguez, CA, USA) to remove small molecular components such as ginsenosides and other components that might remain in the fraction. We named this fraction as crude gintonins, which does not contain ginsenosides.

\section{Isolation of individual gintonins from crude gintonins}

Crude gintonins from butanol extract of Korean red ginseng dissolved in phosphate buffer saline (PBS) ( $\mathrm{pH}$ 7.2) was loaded onto a column packed with DEAE sepharose CL-6B (GE Healthcare) and equilibrated with PBS (pH 7.2). The unbound materials were eluted with the same buffer and the bound materials were eluted with a linear gradient of 0 to $2 \mathrm{M} \mathrm{NaCl}$ in PBS (pH 7.2). Fractions $(10 \mathrm{~mL})$ were collected with a flow rate $1 \mathrm{~mL} /$ min and monitored at $280 \mathrm{~nm}$. Each fraction was assayed for CaCC activity of Xenopus oocytes. The active fractions were selected and pooled into two groups, early eluted unbound active fraction (gintonin E) and late eluted bound active fraction (gintonin L). Each pooled group was concentrated by CentriVap DNA vacuum 
concentrator (Labconco, Kansas City, MO, USA) and chromatographed on Superdex 75 gel filtration column $(10 \times 300 \mathrm{~mm})$ using PBS $(\mathrm{pH} 7.2)$ as an eluent. Fractions were collected with a flow rate $0.5 \mathrm{~mL} / \mathrm{min}$ and monitored at $280 \mathrm{~nm}$. Each pooled gintonin $\mathrm{E}$ and $\mathrm{L}$ fraction was dialyzed against $\mathrm{H}_{2} \mathrm{O}$ and tested for $\mathrm{CaCC}$ activation. The pooled gintonin $\mathrm{E}$ fractions were again loaded onto a DEAE anion exchange column (HiTrap ${ }^{\mathrm{TM}}$ DEAE FF, 1 $\mathrm{mL}$ ) and first equilibrated with $20 \mathrm{mM}$ Tris- $\mathrm{HCl}(\mathrm{pH} 8.0)$. The bound substances were eluted by four step gradients of $20 \mathrm{mM}$ Tris- $\mathrm{HCl}(\mathrm{pH} \mathrm{8.0)}$ containing 100, 150, 200, and $250 \mathrm{mM} \mathrm{NaCl}$ at a flow rate of $1 \mathrm{~mL} / \mathrm{min}$. Each peak containing 100, 150, and $200 \mathrm{mM} \mathrm{NaCl}$ eluent, after extensive dialysis and concentration, were again applied to the DEAE anion exchange column with a linear gradient of $0-1 \mathrm{M} \mathrm{NaCl}$ in $20 \mathrm{mM}$ Tris- $\mathrm{HCl}(\mathrm{pH} 8.0)$ and were finally applied to Superdex 75 gel filtration chromatography to confirm the single peak. Three single peaks obtained from DEAE anion exchange and Superdex 75 gel filtration chromatographies were named as gintonin E1 (3.7 mg), E2 (26.7 mg), and E3 (13.5 mg). Similarly, the pooled gintonin $\mathrm{L}$ fractions were also applied to the DEAE anion exchange column (HiTrap ${ }^{\mathrm{TM}}$ DEAE FF, 1 $\mathrm{mL}$ ) and equilibrated with PBS (pH 7.2). The bound gintonin $\mathrm{L}$ fractions were eluted by five step gradients with PBS (pH 7.2) containing 150, 200, 250, 300, and 400 $\mathrm{mM} \mathrm{NaCl}$ at flow rate $1 \mathrm{~mL} / \mathrm{min}$. Three peaks obtained from PBS ( $\mathrm{pH}$ 7.2) containing only 150, 200, and 250 $\mathrm{mM} \mathrm{NaCl}$ eluent were collected and were subjected to extensive dialysis and concentration. These peaks were again applied to linear gradient DEAE anion exchange chromatography with a gradient of $0-1 \mathrm{M} \mathrm{NaCl}$ in PBS (pH 7.2) to confirm the single peak. Finally, these peaks were applied onto Superdex 75 gel filtration chromatography to obtain a final single peak. These single peaks obtained from DEAE anion exchange and Superdex 75 gel filtration chromatographies were named as gintonin L1 (7.4 mg), L2 (17.6 mg), and L3 (6.6 mg) (Fig. 1).

\section{Molecular mass determination of gintonin by gel fil- tration}

The molecular weights of gintonins were determined by gel filtration chromatography using the method from Yamamoto et al. [15]. Gel filtration chromatography was carried out using a Superdex 75 column $(10 \times 300 \mathrm{~mm})$ equilibrated with PBS (pH 7.2) on BioLogic DuoFlow ${ }^{\mathrm{TM}}$ chromatography systems (Bio-Rad). Fractions were collected with a flow rate of $0.5 \mathrm{~mL} / \mathrm{min}$ and monitored at $280 \mathrm{~nm}$. The molecular weights of gintonins were determined using a calibration curve consisting of standard proteins such as $\operatorname{IgG}(160,000 \mathrm{Da})$, bovine serum albumin (BSA; 67,000 Da), $\beta$-lactoglobulin $(35,000 \mathrm{Da})$, cytochrome $\mathrm{C}(12,327 \mathrm{Da})$, and aprotinin $(6,512 \mathrm{Da})$.

\section{Electrophoresis}

The individual purified gintonins was subjected to SDS-PAGE using $12.0 \%$ separating gel [16]. Crude gintonins, gintonin E1-E3, or L1-L3 (100 $\mu$ g each) was loaded in each lane. After electrophoresis, gintonin bands were visualized by Coomassie Brilliant Blue R-250 staining. For glycoprotein detection, gels were stained using periodic acid-Schiff base staining (PAS). The gel was incubated in $40 \%$ EtOH-7\% acetic acid in $\mathrm{H}_{2} \mathrm{O}$ for $30 \mathrm{~min}$ and then with $1 \%$ periodic acid-3\% acetic acid for $1 \mathrm{~h}$. The periodic acid solution was removed and Schiff's reagent was added and incubated for $1 \mathrm{~h}$. Bands of stained glycoproteins developed a pink color and the PAS-stained gels were stored in water after soaking in 7.5\% acetic acid.

\section{Gintonin amino acid composition analysis}

Gintonin $(30 \mu \mathrm{g})$ was hydrolyzed in vacuo in $6 \mathrm{~N} \mathrm{HCl}$ for $24 \mathrm{~h}$ at $110^{\circ} \mathrm{C}$ for general amino acid analysis. For the analysis of cysteine, gintonin was hydrolyzed in $6 \mathrm{~N}$ $\mathrm{HCl}$ for $24 \mathrm{~h}$ at $110^{\circ} \mathrm{C}$ after peroxidation treatment with formic acid:hydrogen peroxide $=10: 1$. For the analysis of tryptophan, the sample was hydrolyzed in $4 \mathrm{M}$ methanesulfonic acid and $4 \mathrm{M}$ potassium hydroxide was also added. Amino acids converted to phenylisothiocyanate derivates were analyzed by high performance liquid chromatography (HP 1100; Hewlett-Packard, Palo Alto, CA, USA) with Waters Nova-Pak C18 column $(3.9 \times 300$ $\mathrm{mm}$ ) at the Korea Basic Science Institute (Seoul, Korea). Protein contents were determined by the Bradford method using BSA as a standard [17].

\section{Partial amino acid sequence of gintonins}

$\mathrm{N}$-terminal amino acid sequencing of gintonin was performed by automated Edman degradation on a gas-phase protein sequencer model 477A (Applied Biosystems, Foster City, CA, USA) and on a MilliGen 6600 solidphase sequencer (Milligen, Millford, MA, USA). Individual gintonin (100 $\mu \mathrm{g}$ each) was applied to a $12 \%$ SDS-PAGE and protein band was visualized by Coomassie Brilliant Blue R-250 staining. The band was cut and subjected to in-gel digestion with trypsin. The digestion products were desalted and concentrated. All mass spectrometer (MS/MS) of peptides generated by the ingel digestion was performed by nano-electrosprary on a MS (QTOP II; Micromass, Manchester, UK) at the Korea Basic Science Institute. Product ions were analyzed us- 


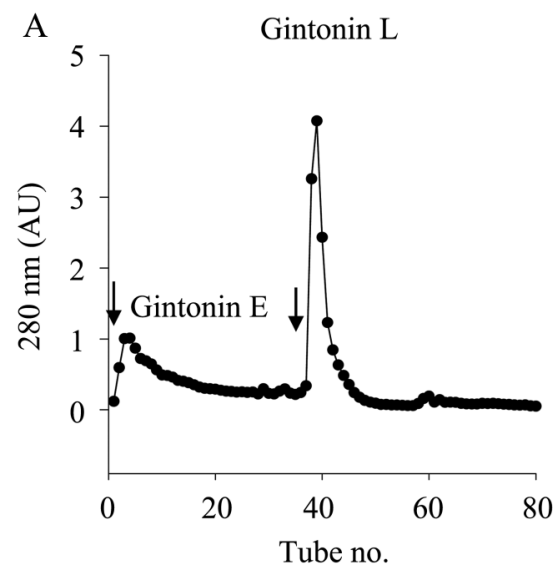

$\mathrm{C}$

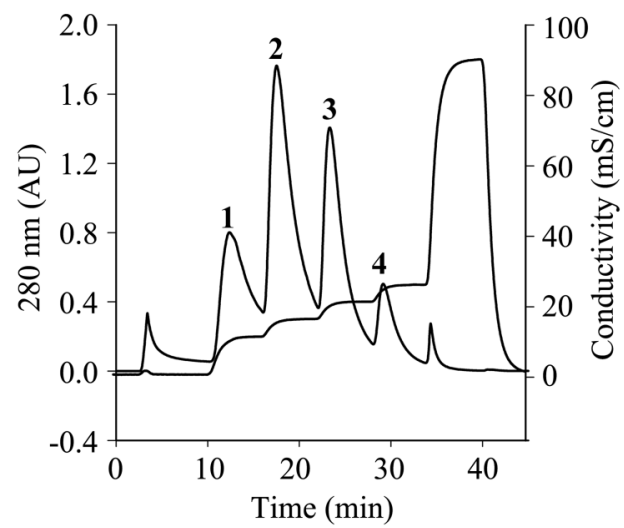

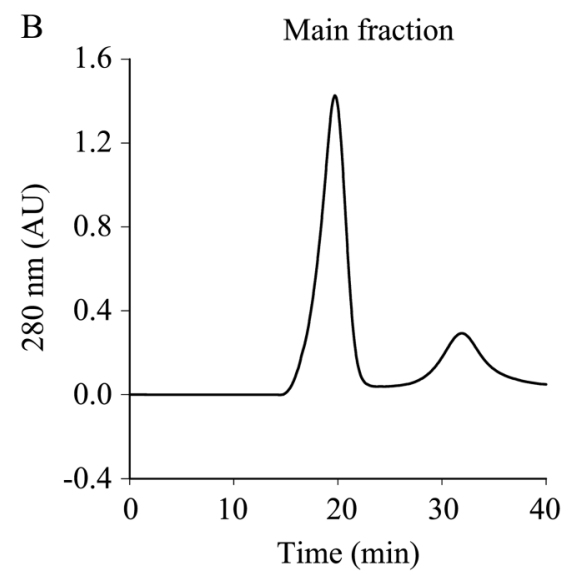

D

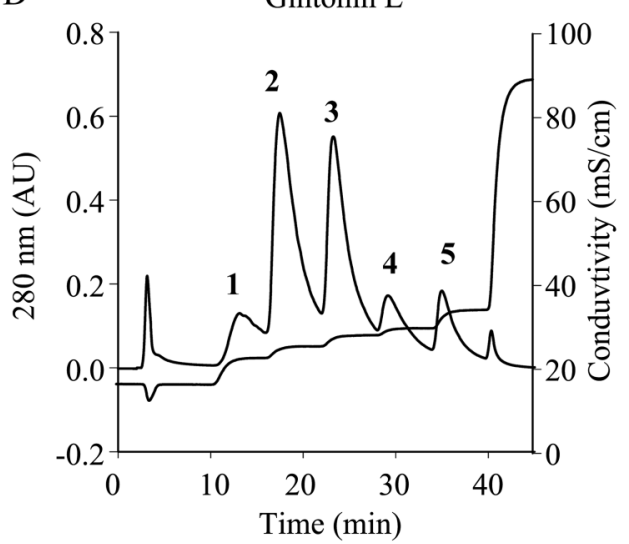

Fig. 1. Crude gintonin includes six individual gintonins with $\mathrm{Ca}^{2+}$-activated $\mathrm{Cl}^{-}$channel activation in Xenopus oocytes. (A) Crude gintonin was separated into gintonin $E$ and $L$ fractions using DEAE sepharose $C L-6 B$ anion exchange chromatogram. Gintonin $E$ fraction (first arrow) was eluted with phosphate buffer saline (PBS) (pH 7.2) and gintonin L fraction (second arrow) was eluted with a linear gradient of 0 to $2 \mathrm{M} \mathrm{NaCl}$ in PBS (pH 7.2). (B) The representative Superdex 75 gel filtration chromatogram with PBS (pH 7.2) of gintonin $L$ fraction obtained from (A). The gel filtration chromatograms of gintonin $E$ also exhibited a similar elution pattern with gintonin L. (C,D) Stepwise gradient DEAE anion exchange chromatogram of gintonin $E$ and $L$ fraction.

ing an orthogonal time-of-flight (TOF) analyzer fitted with a reflector, a microchannel plate detector, and a time-to-digital converter. The data were processed using a personal computer running Mass Lynx software on the Window NT environment. The sequence homologues were searched for using the BLAST program (http:// www.ncbi.mlm.nih.gov/BLAST.cgi).

\section{Carbohydrate composition}

Individual gintonins (2.0 $\mathrm{mg}$ each) were hydrolyzed in $2 \mathrm{M}$ trifluoroacetic acid for $4 \mathrm{~h}$ at $100^{\circ} \mathrm{C}$ for neutral sugar and hydrolyzed in $6 \mathrm{~N} \mathrm{HCl}$ for $4 \mathrm{~h}$ at $100^{\circ} \mathrm{C}$ for amino sugar and acid sugar in glass. Carbohydrate compositions of gintonins were analyzed by high performance anion exchange chromatography-pulsed ampherometric detection system (HPAEC-PAD system; Dionex, Sunnyvale, CA, USA) with a CarboPac ${ }^{\mathrm{TM}}$ PA1 column at the Carbohydrate Bioproduct Research Cen- ter, Sejong University (Seoul, Korea). The molar ratios of monosaccharides were calculated from peak areas. The carbohydrate contents were also determined by phenol-sulfuric acid method for neutral sugar [18] and anthrone method for acid sugar [19].

\section{Lipid composition analysis}

Individual gintonins (1.0 mg each) were hydrolyzed in $6 \mathrm{~N} \mathrm{HCl}$ for $4 \mathrm{~h}$ at $100^{\circ} \mathrm{C}$ or digested by lipoprotein lipase to confirm lipid and hydrophobic moiety. Acid hydrolyzed or digested gintonins were partitioned between distilled water and $n-\mathrm{BuOH}$. The $n$-BuOH layer, after concentration, was further partitioned between distilled water and $n$-hexane. The $n$-hexane layer was prepared for lipid and hydrophobic moiety analysis by an Agilent $6890 \mathrm{~N}$ gas chromatography (GC)-MS system (Agilent Technologies, Palo Alto, CA, USA) with a DB5-MS capillary column $(30 \mathrm{~cm} \times 250 \mu \mathrm{m} \times 0.25 \mu \mathrm{m})$ at the Korea Ba- 
sic Science Institute and by GC (Agilent 6890N) equipped with flame ionization detector and a split injection system and fitted with a supelco SPB-1 capillary column (15 $\mathrm{m} \times 0.32 \mathrm{~mm}$ inside diameter, $0.25 \mathrm{~mm}$ thickness).

\section{Oocyte preparation and measurements of endog- enous CaCC in Xenopus oocytes}

Collection of Xenopus laevis oocytes and recording of endogenous $\mathrm{CaCC}$ in Xenopus laevis oocytes were performed as described in previous reports [11].

\section{EAT cell preparation, loading of EAT cells with fura 2-AM, and fluorescence measurements of $\left[\mathrm{Ca}^{2+}\right]_{i}$ in cell suspensions}

EAT cells were maintained in male mice by weekly intraperitoneal transplantation into fresh mice. The Ehrlich cells were harvested as described by Jorgensen et al. [20]. EAT cell preparation, loading of EAT cells with fura 2-AM, and fluorescence measurements of $\left[\mathrm{Ca}^{2+}\right]_{\mathrm{i}}$ in cell suspensions were performed as described by Jorgensen et al. [20]. $\left[\mathrm{Ca}^{2+}\right]_{\mathrm{i}}$ was estimated in fura 2-loaded cells in suspension using a RF-5300PC intracellular ion measurement system (Shimadzu Corporation, Kyoto, Japan). Briefly, the fura 2-AM loaded cells were diluted with experimental medium to a final $2-4 \times 10^{6} / \mathrm{mL}$ and transferred to polystyrene cuvettes (Elkay Ultra-VU; Elkay Products, Shrewsbury, MA, USA). The cells were stirred using Teflon-coated magnets, and the cuvette housing was thermostatically controlled at $37^{\circ} \mathrm{C}$. The excitation wavelengths were alternated between 340 and $380 \mathrm{~nm}$ under computer control. Emission was detected at $510 \mathrm{~nm}$. Excitation and emission slit widths were $5 \mathrm{~nm}$. Background correction was performed as described in Jorgensen et al. [20]. Digitonin and ethylene glycol tetraacetic acid were used as concentration adjustment reagents to make states in which fura 2 completely combines with and disassociates from $\mathrm{Ca}^{2+}$. All experiments were conducted at $37^{\circ} \mathrm{C}$. Finally, estimation of $\left[\mathrm{Ca}^{2+}\right]_{\mathrm{i}}$ from fura 2 measurements was performed as described in previous report [21].

\section{Data analysis}

To obtain the concentration-response curve in the presence of crude gintonin or purified individual gintonins the observed peak amplitudes were normalized and plotted using Origin software (MicroCal, Northampton, MA, USA). The $\mathrm{EC}_{50}$ is the concentration of crude gintonin or individual gintonins producing half-maximum effect of the control response to crude gintonin or individual gintonins and was calculated as described in previous report [11]. All values are presented as means \pm SEM.

\section{RESULTS AND DISCUSSION}

\section{Separation of crude and individual gintonins from CGSF of ginseng}

We first prepared large amounts of CGSF through butanol extraction and performed the massive silica gel chromatography with composition of solvents $\left(\mathrm{CHCl}_{3}: \mathrm{MeOH}: \mathrm{H}_{2} \mathrm{O}=13: 7: 2\right)$. The fraction causing $\mathrm{CaCC}$ activations in Xenopus oocytes was further subjected to silica gel chromatography with different solvent compositions (EtOH:EtOAc: $\mathrm{H}_{2} \mathrm{O}=3: 1: 0.5$ ). We found that the fraction causing $\mathrm{CaCC}$ activations was high molecular ingredients. So, we performed further extensive dialysis (pore size, 6,000-8,000) of the active fraction to remove the remaining low molecular components and named as a crude gintonin fraction, which was devoid of ginsenosides and other small molecules in ginseng.

Crude gintonin fraction was first subjected to DEAE Sepharose anion-exchange chromatography using PBS (pH 7.2) containing 0 to $2 \mathrm{M} \mathrm{NaCl}$ as an eluent and this procedure produced two major peaks with $\mathrm{CaCC}$ activations (Fig. 1A). We named major peak 1 as early eluted gintonin (gintonin $\mathrm{E}$ ), unbound active fraction and major peak 2 as late eluted gintonin (gintonin L), bound active fraction. We further performed gel filtration chromatography using the pooled gintonin $\mathrm{E}$ and $\mathrm{L}$ fractions and obtained one main peak with higher molecular weights and minor peaks in gintonin $\mathrm{E}$ and $\mathrm{L}$ fractions (Fig. 1B). The pooled main peaks causing $\mathrm{CaCC}$ activations of gintonin $\mathrm{E}$ fractions were again eluted by stepwise gradient anion exchange chromatography with a buffer of $20 \mathrm{mM}$ Tris- $\mathrm{HCl}(\mathrm{pH}$ 8.0) containing 100, 150, 200, and $250 \mathrm{mM} \mathrm{NaCl}$, and this procedure produced four peaks (Fig. 1C). In these peaks, the first, second, and third peaks but not the fourth peak mainly caused $\mathrm{CaCC}$ activations (data not shown). The pooled main peaks of gintonin $\mathrm{L}$ fractions were also eluted by stepwise gradient anion exchange chromatography with PBS ( $\mathrm{pH}$ 7.2) containing 150, 200, 250, 300, and $400 \mathrm{mM} \mathrm{NaCl}$ (Fig. 1D). In these peaks, the first, second, and third peaks, but not the fourth and fifth peaks, also mainly caused CaCC activations (data not shown). Thus, we were able to obtain six different individual gintonins from gintonin $\mathrm{E}$ and $\mathrm{L}$ fractions associated with $\mathrm{CaCC}$ activation in Xenopus oocytes. We named them as gintonin E1, E2 and E3 or gintonin L1, L2 and L3, depending on their elution patterns after DEAE-anion exchange chromatography (Fig. 1). The purity of these individual gintonins 
was confirmed by the following gel filtration chromatography and further linear anion exchange chromatography and SDS-PAGE (Figs. 2 and 3). The final yields of gintonin E1 (3.7 mg), E2 (26.7 mg), E3 (13.5 mg), L1 (7.4 $\mathrm{mg}$ ), L2 (17.6 mg), and L3 (6.6 mg) from CGSF (908 g) were $0.0004 \%, 0.0029 \%, 0.0015 \%, 0.0008 \%, 0.0019 \%$, and $0.0007 \%$, respectively.

\section{Determination of molecular weight of gintonin}

Although most of individual gintonins were eluted at the same time in gel filtration chromatography (Fig. $2 \mathrm{~A}, \mathrm{C}$ ), they showed slightly different elution patterns in $\mathrm{NaCl}$ gradient application (Fig. 2B, D), revealing the possibility that their molecular weights are almost same but the charges that they carry might differ between them. We determined the molecular weight of gintonin L2 as a representative gintonin using standard proteins and found that the molecular weight of gintonin L2 was about $67 \mathrm{kDa}$ (Fig. 3A). The native molecular weights of other gintonins were also about $67 \mathrm{kDa}$ (data not shown). Interestingly, in SDS-PAGE six individual gintonins showed a broad but single major band and its apparent molecular weight was about $13 \mathrm{kDa}$, showing a possibility that gintonins are of a pentameric nature (Fig. 3B).

\section{De novo sequence and amino acid composition of indi- vidual gintonins}

Purified gintonins were subjected to N-terminal amino acid sequencing by automated Edman degradation. We could not obtain full amino acid sequences of gintonin because of N-terminal blocking. We could only obtain several partial internal peptides sequences from trypsinized gintonins using MALDI-TOF-MS/MS. The amino acid sequences did not show any homologies with known plant proteins (data not shown). The contents of total proteins in gintonins by Bradford method were about $9.4,24.1,20.5,35.8,37.1$, and $39.6 \%$ for gintonin E1, E2, E3, L1, L2, and L3, respectively. Thus, protein
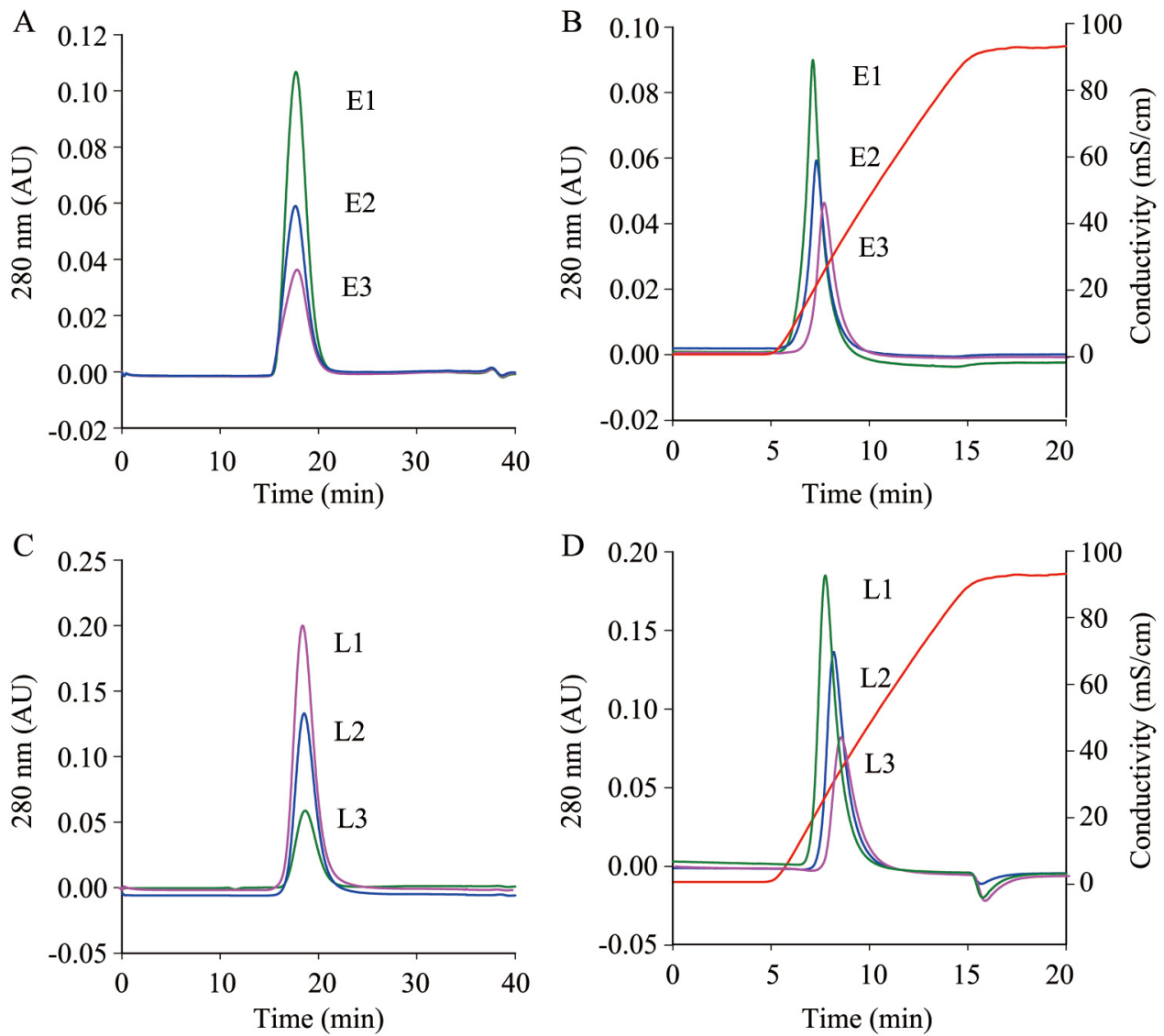

Fig. 2. Elution patterns of individual gintonins by gel chromatography or continuous anion exchange chromatography. (A,C) Overlay of gel filtration chromatograms on Superdex 75 column with phosphate buffer saline (pH 7.2) of purified gintonin E1, E2, E3, L1, L2, and L3. (B,D) Overlay of anion exchange chromatograms of purified gintonin E1, E2, E3, L1, L2, and L3. Analysis through two chromatograms shows that the individual gintonins are isolated as a single peak, reflecting that the molecular weights of six individual gintonins are almost same $(A, C)$ but that the charges that they carry might differ between them $(B, D)$. 
A

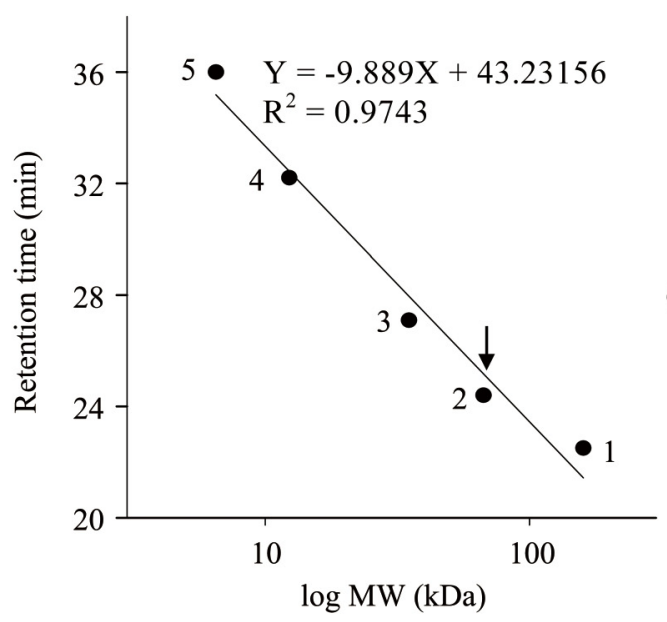

B

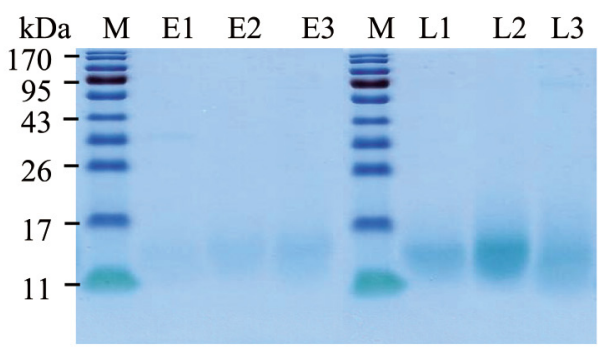

$\mathrm{C}$

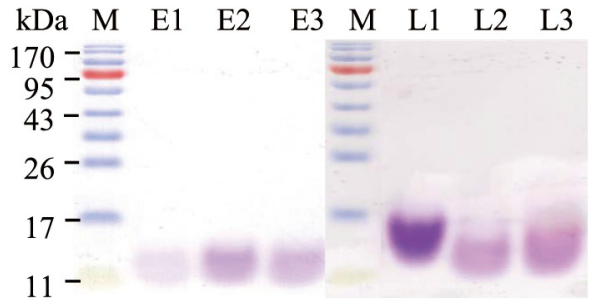

Fig. 3. Determination of molecular weight of gintonin and gel staining of carbohydrate components of individual gintonins. (A) Determination of molecular weight of gintonin through gel filtration chromatography. Gel filtration chromatogram of gintonin L2 in Superdex 75 column with phosphate buffer saline (pH 7.2). The numbers represent standard proteins used: 1) IgG (160 kDa), 2) bovine serum albumin (BSA) (67 kDa), 3) $\beta$-lactoglobulin $(35 \mathrm{kDa}), 4)$ cytochrome $C(12 \mathrm{kDa}), 5)$ aprotinin $(6.5 \mathrm{kDa})$. The arrow indicates gintonin $\mathrm{L} 2$ that is almost coincided with BSA standard. (B) Determination of molecular weight of gintonin through SDS-PAGE. M represents molecular markers. Comassie Brilliant blue staining was used to stain protein moieties of gintonins. Six gintonins in SDS-PAGE showed that apparent molecular weight of gintonins is about 13 $\mathrm{kDa}$. (C) Periodic acid-schiff staining demonstrates that individual gintonins contain carbohydrate moiety and shows that the amount of carbohydrate moiety of each gintonin differs between them.

contents of gintonin L1-L3 were about three times higher than those of gintonin E1. Amino acid composition of individual gintonins was summarized in Table 1.

\section{Carbohydrate and lipid composition of individual gintonins}

As shown in Fig. 3B, since the bands of individual gintonins from SDS-PAGE are single but broad and are not strongly stained with Comassie brilliant blue staining, there is a possibility that gintonin might contain carbohydrate moieties. Therefore, we used PAS technique to know whether gintonin contains carbohydrates. Individual gintonins were strongly stained by PAS as shown in Fig. 3C. Next, we examined carbohydrate composition of gintonins using HPAEC-PAD system. Table 2 showed that carbohydrate compositions of six gintonins were almost similar to each other. Glucose was major component, while rhamnose, mannose, and xylose were minor. Interestingly, galactose and mannose in gintonin L1-L3 was not detected (Table 2). Finally, the content of total carbohydrate in gintonins were about $34.3,45.3$, $38.1,36.0,29.8$, and $45.2 \%$ for gintonin E1, E2, E3, L1, $\mathrm{L} 2$, and L3, respectively. The above results again confirmed that gintonins are glycoproteins.

Since gintonins were co-fractionated with ginsenosides by butanol extraction, we examined the possibility that
Table 1. Amino acid composition of gintonins

\begin{tabular}{lrrrrrr}
\hline Amino acid & \multicolumn{1}{c}{ E1 } & \multicolumn{1}{c}{ E2 } & \multicolumn{1}{c}{ E3 } & \multicolumn{1}{c}{ L1 } & \multicolumn{1}{c}{ L2 } & \multicolumn{1}{c}{ L3 } \\
\hline CYA & 2.90 & 3.87 & 1.29 & 0.97 & 1.14 & 0.94 \\
ASX & 8.27 & 8.60 & 6.11 & 1.89 & 3.71 & 3.98 \\
GLX & 6.67 & 7.22 & 4.57 & 2.43 & 4.89 & 4.25 \\
Ser & 4.57 & 4.29 & 3.29 & 2.29 & 5.00 & 3.59 \\
Gly & 12.40 & 13.67 & 11.55 & 12.88 & 11.57 & 10.56 \\
His & 0.00 & 0.00 & 0.00 & 0.00 & 0.00 & 0.00 \\
Arg & 1.68 & 1.85 & 1.19 & 0.63 & 1.69 & 1.10 \\
Thr & 3.11 & 3.29 & 2.20 & 1.37 & 1.46 & 1.79 \\
Ala & 5.62 & 6.98 & 3.59 & 4.52 & 4.07 & 4.67 \\
Pro & 4.52 & 4.90 & 3.30 & 3.18 & 3.09 & 4.86 \\
Tyr & 0.00 & 0.00 & 0.00 & 0.00 & 0.00 & 0.00 \\
Val & 3.13 & 3.89 & 3.74 & 3.99 & 4.68 & 6.00 \\
Met & 0.00 & 0.00 & 0.00 & 0.00 & 0.00 & 0.00 \\
Ile & 6.03 & 5.16 & 7.54 & 10.36 & 8.83 & 7.76 \\
Leu & 3.96 & 5.09 & 3.43 & 4.26 & 6.83 & 10.09 \\
Phe & 26.40 & 18.66 & 35.10 & 28.89 & 21.37 & 22.47 \\
Trp & 3.59 & 7.10 & 3.62 & 4.88 & 8.13 & 6.10 \\
Lys & 7.14 & 5.42 & 9.78 & 17.48 & 13.56 & 11.85
\end{tabular}

Data are presented as percentage.

The detail methods for amino acid compositions of each gintonin are described in Materials and Methods.

CYA, the sum of cysteine and cystine; ASX, the sum of asparagine and aspartic acid, GLX, the sum of glutamine and glutamic acid. 
Table 2. Carbohydrate composition of gintonins

\begin{tabular}{lcccccc}
\hline Carbohydrate & E1 & E2 & \multicolumn{1}{c}{ E3 } & L1 & \multicolumn{1}{c}{ L2 } & \multicolumn{1}{c}{ L3 } \\
\hline Rhamnose & 0.86 & 1.02 & 0.91 & 1.11 & 0.93 & 1.09 \\
Arabinose & 5.66 & 5.10 & 5.66 & 9.11 & 8.32 & 7.36 \\
Glucose & 84.84 & 84.41 & 83.97 & 77.16 & 74.64 & 71.59 \\
Manose & & & & 1.76 & 2.30 & 3.37 \\
Xylose & 1.12 & 0.94 & 0.95 & 2.73 & 2.55 & 2.50 \\
Glucosamine & 7.52 & 8.53 & 8.51 & 8.13 & 11.26 & 14.09
\end{tabular}

Data are presented as percentage.

The detail methods for carbohydrate compositions of each gintonin are described in Materials and Methods.

gintonin also contained lipid moieties. As shown in Table 3, individual gintonins contained fatty acids such as palmitic, stearic, oleic and linoleic acids. The portion of polyunsaturated fatty acid, linoleic acid in gintonin E1 and L1 were higher than saturated fatty acids such as palmitic and stearic acid or oleic acid. Palmitic acid was predominant in gintonin E2, E3, L2, and L3. Next, we estimated total contents of lipid moiety in gintonins by GC. The contents of total lipids in gintonins were 20.7, 4.4, 2.4, 11.0, 6.2 and $7.0 \%$ for gintonin E1, E2, E3, L1, L2 and L3, respectively. Thus, gintonin E1 has the highest lipid contents among them. These results indicate that gintonins are novel glycolipoproteins.

\section{Effects of crude and individual gintonins on endog- enous $\mathrm{CaCC}$ in Xenopus oocytes}

We examined whether gintonin but not ginsenosides induce $\mathrm{CaCC}$ activation. As shown in Fig. 4, treatment of crude gintonin from Korean red ginseng and American ginseng induced inward $\mathrm{Cl}^{-}$currents in a concentration-dependent manner at $-70 \mathrm{mV}$ holding potential (Fig. 4A). The $\mathrm{ED}_{50}$ was $4.0 \pm 0.2$ and $4.4 \pm 0.5 \mu \mathrm{g} / \mathrm{mL}$ for Korean red ginseng and American ginseng (Fig. 4C), respectively. Individual ginsenosides tested had no effects on $\mathrm{CaCC}$ activity at low and high concentrations (Fig. 4C). Next, we examined the effects of individual gintonin E1, E2 and E3 or gintonin L1, L2 and L3 on CaCC activation in Xenopus oocytes. As shown in Fig. 4D, we found that gintonin E1, E2, and E3 showed almost the same degree of effects on $\mathrm{CaCC}$ activation. The $\mathrm{ED}_{50}$ values were $1.5 \pm 0.1,2.3 \pm 0.1,1.5 \pm 0.1 \mu \mathrm{g} / \mathrm{mL}$ for $\mathrm{E} 1, \mathrm{E} 2$ and $\mathrm{E} 3$, respectively. Interestingly, although gintonin L1 showed almost the same degree of effects on $\mathrm{CaCC}$ activation with $\mathrm{E} 1$ to $\mathrm{E} 3$, gintonin $\mathrm{L} 2$ and $\mathrm{L} 3$ showed weaker $\mathrm{CaCC}$ activation than other individual gintonins. The $\mathrm{ED}_{50}$ values were $1.0 \pm 0.1,3.2 \pm 0.2$, and $4.3 \pm 0.2 \mu \mathrm{g} /$ $\mathrm{mL}$ for L1, L2 and L3, respectively. Thus, these results indicate that although individual gintonins are similar to each other in molecular weights and physico-chemical properties, there are slight differences in activating $\mathrm{CaCC}$ in Xenopus oocytes among individual gintonins.

\section{Effect of gintonin or ginsenosides on $\left[\mathrm{Ca}^{2+}\right]_{i}$ in mouse Ehrlich ascite tumor cells}

Treatment of GTP-binding protein coupled receptor agonists in fura 2-AM-loaded mouse EAT cells induces transient increases in $\left[\mathrm{Ca}^{2+}\right]_{i}$. In the present study, we examined whether gintonin or individual ginsenosides such as ginsenoside $\mathrm{Ra}, \mathrm{Rb}_{1}, \mathrm{Rb}_{2}, \mathrm{Rc}$ and $\mathrm{Rg}_{1}$ exhibit their effects on transient increases in $\left[\mathrm{Ca}^{2+}\right]_{\mathrm{i}}$ in fura 2-AM-loaded EAT cells. Because of limitation of available individual gintonins, we used crude gintonin for the study on elevation of $\left[\mathrm{Ca}^{2+}\right]_{i}$ in mouse EAT cells. When EAT cells in suspension are first treated with ginsenoside alone (each $100 \mu \mathrm{M}$ ), none of the ginsenosides tested induced any responses in EAT cells (Fig. 5A). In contrast to ginsenosides, crude gintonin treatment $(100 \mathrm{ng} / \mathrm{mL})$ caused a transient elevation of $\left[\mathrm{Ca}^{2+}\right]_{\mathrm{i}}$, as illustrated by the data in Fig. 5A. Fig. 5B also shows that the elevation of crude gintonin-induced $\left[\mathrm{Ca}^{2+}\right]_{\mathrm{i}}$ was in a concentration-dependent manner. Interestingly, crude gintonin-induced transient elevation of $\left[\mathrm{Ca}^{2+}\right]_{i}$ was greatly reduced by removal of external $\mathrm{Ca}^{2+}\left(\mathrm{Ca}^{2+}\right.$-free medium in the presence of $0.2 \mathrm{mM}$ EGTA), indicating that extracellular $\mathrm{Ca}^{2+}$ is also required (Fig. 5B). However, treatment of crude gintonin still increased $\left[\mathrm{Ca}^{2+}\right]_{\mathrm{i}}$ in a concentration-dependent manner, indicating that crude gintonin-induced elevation of $\left[\mathrm{Ca}^{2+}\right]_{i}$ is likely due to $\mathrm{Ca}^{2+}$ release from intracellular $\mathrm{Ca}^{2+}$ stores and $\mathrm{Ca}^{2+}$ entry

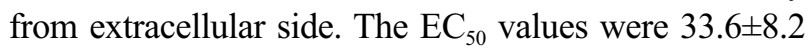

Table 3. Lipids composition of gintonins

\begin{tabular}{|c|c|c|c|c|c|c|}
\hline Lipids & E1 & $\mathrm{E} 2$ & E3 & L1 & L2 & L3 \\
\hline Palmitic acid (16:0), esterform & 29.82 & 57.39 & 56.59 & 36.48 & 41.78 & 39.5 \\
\hline Stearic acid (18:0), esterform & 4.22 & 8.73 & 8.20 & 4.74 & 5.49 & 5.44 \\
\hline Oleic acid (18:1) or oleic acid ester form & 7.08 & 26.06 & 27.52 & 14.32 & 30.04 & 26.64 \\
\hline Linoleic acid (18:2) or linoleic acid ester form & 58.88 & 7.82 & 7.69 & 44.46 & 22.69 & 28.42 \\
\hline
\end{tabular}

Data are presented as percentage.

The detail methods for lipid compositions of each gintonin are described in Materials and Methods. 
A

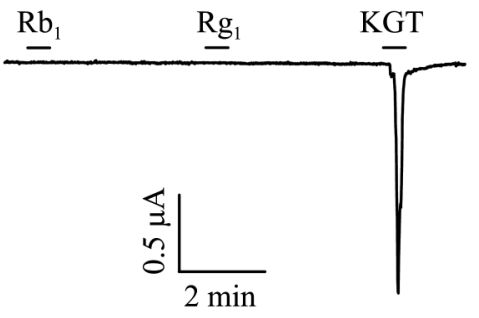

$\mathrm{C}$

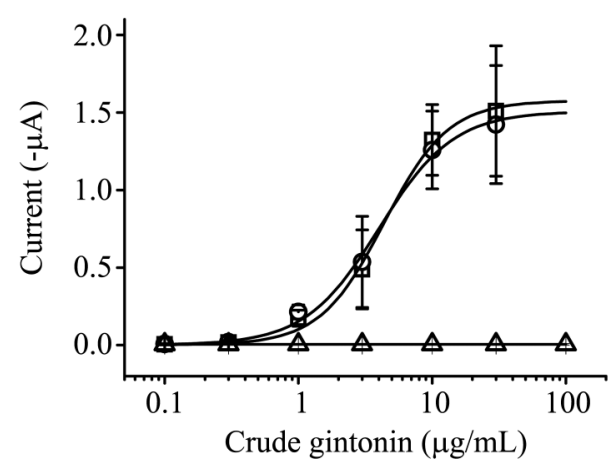

B

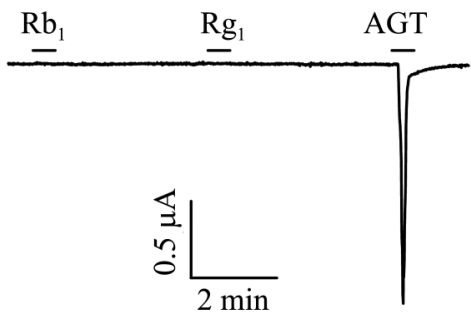

$\mathrm{D}$

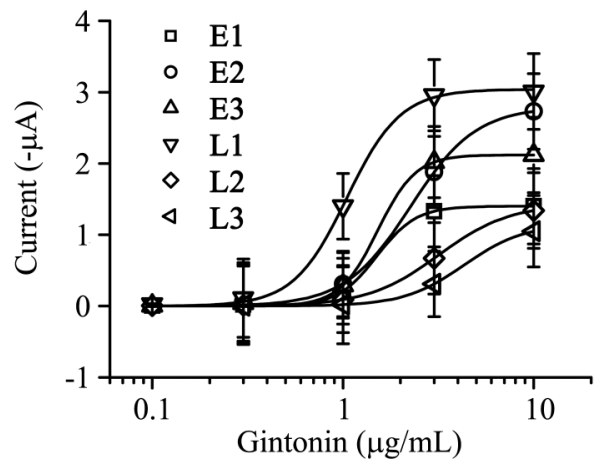

Fig. 4. Crude gintonin and individual gintonins but not ginsenosides activate $\mathrm{Ca}^{2+}$-activated $\mathrm{Cl}^{-}$channel $(\mathrm{CaCC})$ with concentration-dependent manner. (A,B) Treatment of crude gintonin $(10 \mu \mathrm{g} / \mathrm{mL})$ from Korean red ginseng (KGT) (A) or from American ginseng (AGT) (B) induced inward Clcurrents in a concentration-dependent manner, whereas treatment of ginsenoside $\mathrm{Rb}_{1}$ and $\mathrm{Rg}_{1}(100 \mu \mathrm{M}$ each) did not. (C) Crude gintonin from KGT ( $\square$ ), AGT (०), or ginsenoside $\mathrm{Rb}_{1}(\triangle)$ and symbols of other ginsenosides including $\mathrm{Rc}, \mathrm{Rd}, \mathrm{Re}, \mathrm{Rf}$, and $\mathrm{Rg}_{1}$ were omitted for clarification. (D) Individual gintonins increased inward CaCC currents in a concentration-dependent manner. Crude gintonin fraction of AGT (Panax quinquefolis) roots was prepared as described in Materials and Methods. Data represent means \pm SEM $(n=7-8)$.

A

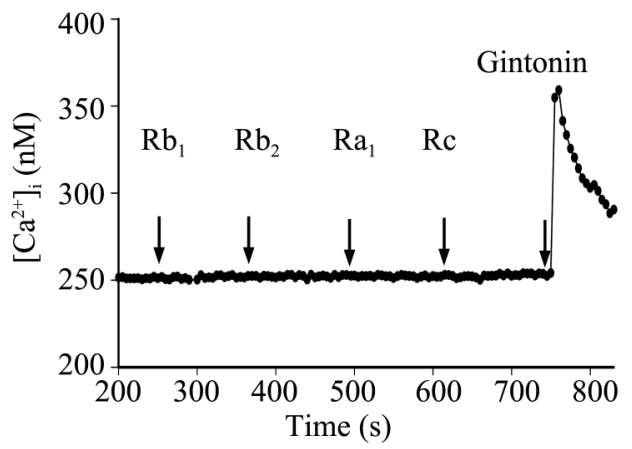

B

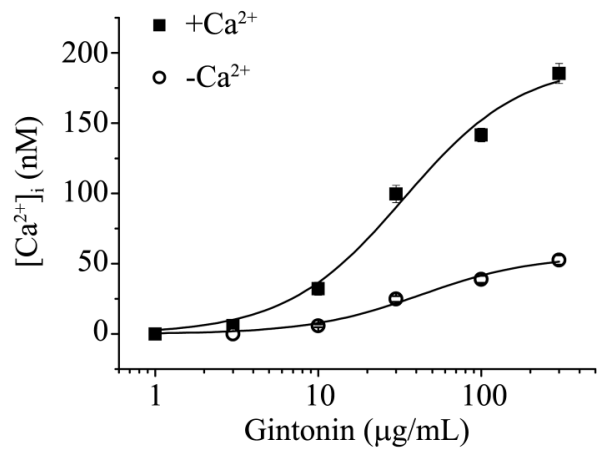

Fig. 5. Gintonin but not ginsenosides elevates $\left[\mathrm{Ca}^{2+}\right]_{i}$ in mouse Ehrlich ascites tumor (EAT) cells. (A) Fura 2 loaded cells $\left(2-4 \times 10^{6} / \mathrm{mL}\right)$ were incubated in $\mathrm{Ca}^{2+}$ buffer $\left(1.5 \mathrm{mM} \mathrm{Ca}{ }^{2+}\right)$ for $10 \mathrm{~min}$. Sequential addition of $100 \mu \mathrm{M}$ ginsenosides such as ginsenoside $R a, \mathrm{Rb}_{1}, \mathrm{Rb}_{2}, \mathrm{Rc}_{\mathrm{and}} \mathrm{Rg} \mathrm{g}_{1}$ did not induce any responses to EAT cells. However, addition of $100 \mathrm{ng} / \mathrm{mL}$ crude gintonin exhibited transient increases of [Ca $\left.{ }^{2+}\right]_{i}$ in fura 2-AM loaded EAT cells. (B) Fura 2 cell loaded cells $\left(2-4 \times 10^{6} / \mathrm{mL}\right)$ were incubated in either $\mathrm{Ca}^{2+}$ buffer $\left(1.5 \mathrm{mM} \mathrm{Ca}^{2+}\right)$ or $\mathrm{Ca}^{2+}$ free buffer $(0.2 \mathrm{mM} \mathrm{EGTA})$ for $10 \mathrm{~min}$. Gintonin transiently increased $\left[\mathrm{Ca}^{2+}\right]_{\mathrm{i}}$ in EAT cells in a concentration-dependent manner. Data are represented as means $\pm S E M(n=5-6 /$ group).

and $43.6 \pm 14.2 \mathrm{ng} / \mathrm{mL}$ in the presence and absence of extracellular $\mathrm{Ca}^{2+}$, respectively. These results indicate that gintonin but not ginsenosides are responsible for elevation of $\left[\mathrm{Ca}^{2+}\right]_{\mathrm{i}}$ in mammalian cells.

\section{Effects of phospholipase $\mathrm{C}$ inhibitor, $\mathrm{IP}_{3}$ receptor antagonist, or $\mathrm{Ca}^{2+}$ chelator on crude gintonin-medi- ated $\mathrm{CaCC}$ activation and $\left[\mathrm{Ca}^{2+}\right]_{\mathrm{i}}$ elevation}

Next, to explain the possible role of PLC on gintoninmediated signaling pathway of increases in cytoplasmic 
$\left[\mathrm{Ca}^{2+}\right]_{\mathrm{i}}$ and $\mathrm{CaCC}$ activations, we first investigated the effect of active PLC inhibitor, U-73122 and inactive analog, U-73343 using Xenopus oocytes and mouse EAT cells. In Xenopus oocytes, crude gintonin-induced CaCC currents in U-73122 were $3.9 \pm 0.3 \%$ of the control, whereas the current in U-73343 was $97.2 \pm 0.2 \%$ of the control (Fig. 6A). These observations indicate that crude gintonin-mediated $\mathrm{CaCC}$ activations are mediated through PLC activation. As a next step, we examined whether or not intracellular $\mathrm{Ca}^{2+}$ release through $\mathrm{IP}_{3}$ receptor was responsible for gintonin-induced $\mathrm{CaCC}$ activations. For this, we tested the effects of $\mathrm{IP}_{3}$ receptor antagonist, membrane permeable 2-aminoethxydiphenyl borate (2-APB) [22], on gintonin-induced $\mathrm{CaCC}$ activation. As shown in Fig. 6B, addition of 2-APB almost completely abolished inward $\mathrm{CaCC}$ currents induced by gintonin (control currents from $1.3 \pm 0.2$ to $0.03 \pm 0.01$ $\mu \mathrm{A})$. In addition, buffering intracellular free $\mathrm{Ca}^{2+}$ by treatment of membrane permeable 1,2-bis-(2-aminophenoxy)ethane-N,N,N',N'-tetraacetic acid acetoxymethyl ester (BAPTA-AM) $(10 \mu \mathrm{M}$ final) also almost abolished gintonin-mediated $\mathrm{CaCC}$ activation (Fig. $6 \mathrm{C}$ ). In mouse EAT cells, Fig. $6 \mathrm{D}$ shows the increase in $\left[\mathrm{Ca}^{2+}\right]_{\mathrm{i}}$ in suspensions of mouse EAT cells in $\mathrm{Ca}^{2+}$-containing or $\mathrm{Ca}^{2+}$ free buffer after addition of gintonin in the presence of the active U-73122 or inactive analog U-73343 $(1 \mu \mathrm{M})$. Thus, application of U-73122 but not U-73343 almost abolished the action of crude gintonin (Fig. 6D). These results again signify that gintonin is the main active components of CGSF for the activation of $\mathrm{CaCC}$ via the phospholipase $\mathrm{C}-\mathrm{IP}_{3}-\mathrm{Ca}^{2+}$ pathway in Xenopus oocytes and mouse EAT cells.

In the present study, we identified novel glycolipoproteins from ginseng root; that we named and refer to as gintonin, which was co-fractionated with ginsenosides during CGSF preparation of ginseng. Gintonin treatment
A

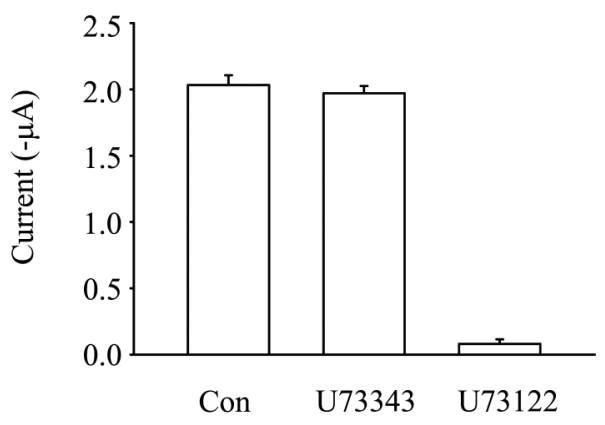

$\mathrm{C}$

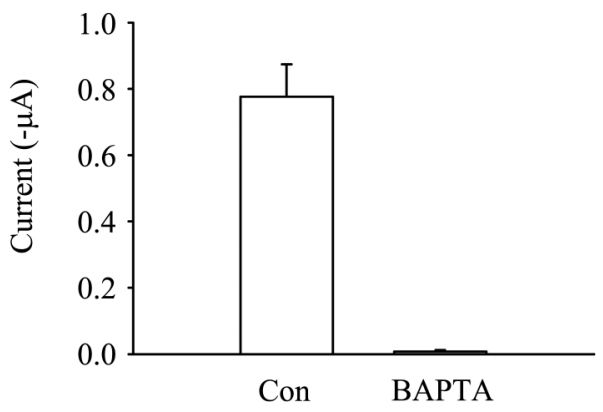

B

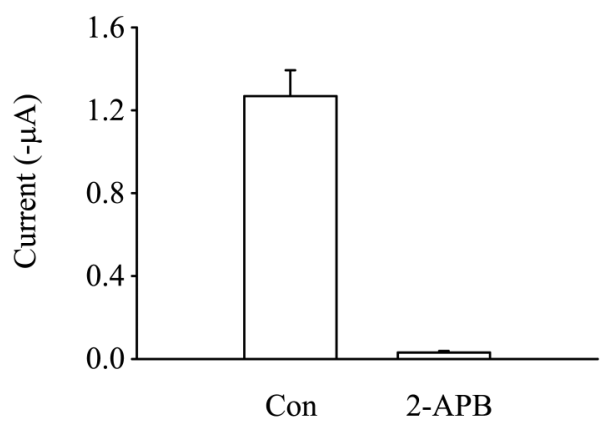

D

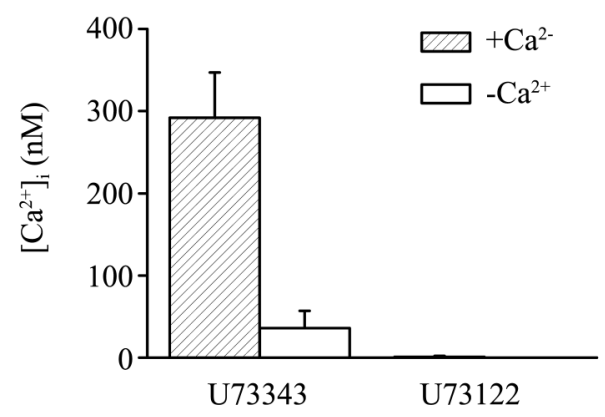

Fig. 6. The activation of $\mathrm{Ca}^{2+}$-activated $\mathrm{Cl}^{-}$channel by gintonin depends on phospholipase $\mathrm{C}$ (PLC) and inositol 1,4,5-trisphosphate receptor activation and intraoocyte $\mathrm{Ca}^{2+}$ in Xenopus oocytes and in Ehrlich ascites tumor (EAT) cells. (A) Histograms of current amplitudes were first measured in the presence of crude gintonin $(10 \mu \mathrm{g} / \mathrm{mL})$ at $-80 \mathrm{mV}$ holding potential and oocytes were perfused for $5 \mathrm{~min}$ with $1 \mu \mathrm{M}$ of either the inactive (U73343) or the active (U73122) inhibitor of PLC. (B) Histograms of current amplitudes measured from oocytes treated with $1 \mu \mathrm{M}$ of either $\mathrm{H}_{2} \mathrm{O}$ (Con) or 2-aminoethxydiphenyl borate (2-APB) prior to recording and incubated for 5 min. (C) Histograms of current amplitudes measured from oocytes treated with $\mathrm{H}_{2} \mathrm{O}$ (Con) or 1,2-bis-(2-aminophenoxy)ethane-N,N,N',N'-tetraacetic acid acetoxymethyl ester (BAPTA-AM) (10 $\mu \mathrm{M}$ final) prior to recording. After $\mathrm{H}_{2} \mathrm{O}$ or BAPTA-AM treated oocytes were further incubated for $2 \mathrm{~h}$ in ND96 medium. Current amplitudes are represented as means \pm SEM $(n=6)$. (D) Effects of active or inactive PLC inhibitor on gintonin-mediated increase in cytoplasmic $\left[\mathrm{Ca}^{2+}\right]_{\mathrm{i}}$ in $\mathrm{EAT}$ cells in $\mathrm{Ca}^{2+}$ buffer $\left(1.5 \mathrm{mM} \mathrm{Ca}^{2+}\right)$ and in $\mathrm{Ca}^{2+}$ free buffer $(0.2 \mathrm{mM} \mathrm{EGTA})$. Pretreatment of active PLC inhibitor (U73122, $\left.10 \mu \mathrm{M}\right)$ but not inactive PLC inhibitor $(\mathrm{U} 73343,10 \mu \mathrm{M})$ blocked gintonin $(100 \mathrm{ng} / \mathrm{mL})$-mediated elevation of $\left[\mathrm{Ca}^{2+}\right]_{\mathrm{i}}$ in $\mathrm{Ca}^{2+}$ and $\mathrm{Ca}^{2+}$ free buffer $(0.2 \mathrm{mM}$ EGTA). Data are represented as means \pm SEM ( $n=4-5 /$ group$)$. 
induced a transient elevation of $\left[\mathrm{Ca}^{2+}\right]_{\mathrm{i}}$ in mouse EAT cells and caused activation of $\mathrm{CaCC}$ in Xenopus oocytes, whereas individual ginsenosides did not. However, in water-soluble fractions of ginseng, which might also contain proteins and polysaccharides, and in petroleum ether extracts of ginseng that might contain main lipid soluble components, we could not observe any stimulating effects on $\mathrm{CaCC}$ activations in Xenopus oocytes and elevation of $\left[\mathrm{Ca}^{2+}\right]_{i}$ in mouse EAT cells (data not shown). Thus, these results indicate that gintonin is a novel bioactive ligand derived from ginseng.

It is noteworthy that the amino acid composition of individual gintonins revealed the highest contents of phenylalanine, although we do not currently know the functional role of phenylalanine in gintonin (Table 1). In addition, individual gintonins contain the high abundance of hydrophobic amino acids such as alanine, isoleucine, leucine, phenylalanine, tryptophan, and valine. They might be involved in structural roles in gintonins' chemical and physical properties by forming $\alpha$-helix. Since glucosamine is usually involved in $\mathrm{N}$ - or Olinkages of carbohydrate and proteins of glycoproteins, it shows a possibility that glucosamine might couple to asparagine, serine, or threonine of gintonins (Table 1) [23]. In the present study we also found that gintonin contained lipid components. The lipid analysis revealed that individual gintonins also contain palmitic, oleic, linoleic, and stearic acids. Interestingly, gintonin E1 contains linoleic acid more than seven times compared to E2 and E3. Gintonin L1 also contains linoleic acid near twice compared to L2 and L3 (Table 3). However, we could not exclude the possibility that gintonin content or composition is variable from batch-to-batch and from different sources of ginseng. Further studies will be needed to establish standardization of gintonin.

In present study we further revealed that gintonin from ginseng induced $\mathrm{CaCC}$ activation in Xenopus oocytes and transiently elevate $\left[\mathrm{Ca}^{2+}\right]_{\mathrm{i}}$ in mouse EAT cells. However, treatment of active PLC inhibitor U73122 but not inactive PLC inhibitor, $\mathrm{U} 73343, \mathrm{IP}_{3}$ receptor antagonist, 2-APB or buffering of $\left[\mathrm{Ca}^{2+}\right]_{\mathrm{i}}$ with membrane permeable BAPTA-AM greatly diminished or abolished gintonin-mediated $\mathrm{CaCC}$ activations in Xenopus oocytes. Thus, gintonin but not ginsenosides are main agents that are responsible for induction of $\mathrm{CaCC}$ activation from CGSF through sequential $\mathrm{PLC}-\mathrm{IP}_{3}-\mathrm{Ca}^{2+}$ pathway. Although CGSF activates $\mathrm{CaCC}$ through $\mathrm{G}_{\mathrm{q}_{111^{-}}}$ phospholipase $\mathrm{C}-\mathrm{IP}_{3}-\mathrm{Ca}^{2+}$ pathway in Xenopus oocytes $[5,6]$ and CGSF treatment also causes transient elevation of $\left[\mathrm{Ca}^{2+}\right]_{\mathrm{i}}$ in EAT cells [24], ginsenosides devoid of gin- tonin failed to activate $\mathrm{CaCC}$ and to elevate $\left[\mathrm{Ca}^{2+}\right]_{\mathrm{i}}$ (Figs. 4 and 5). Thus, in regarding to previous reports on the regulation of $\mathrm{Ca}^{2+}$-related membrane signaling pathways by CGSF $[5,11,12,25]$, the newly identified gintonin is the main active ingredient of CGSF. Interestingly, gintonin isolated from Korean red ginseng or American ginseng did not show much difference in $\mathrm{CaCC}$ activations in Xenopus oocytes (Fig. 4). Taken together, these results further showed the possibility that gintonin rather than ginsenosides might be main contributors of ginseng's multiple pharmacological effects through unidentified membrane component(s). In addition, since ginseng is usually taken through oral route, it might be questioned whether oral administration of gintonin could show the same biological effects as it did in vitro experiments. Thus, in future study, it will be necessary to study gintonin bioavailability for the explanation of gintoninmediated in vivo biological actions through $\left[\mathrm{Ca}^{2+}\right]_{\mathrm{i}}$ regulations.

We for the first time identified that ginseng contains novel glycolipoproteins, which we refer to as gintonin, that cause the mobilization of $\left[\mathrm{Ca}^{2+}\right]_{\mathrm{i}}$ in EAT cells and activation of CaCCs in Xenopus oocytes through wellknown membrane signaling pathways. Since intracellular $\mathrm{Ca}^{2+}$ release is a convergence point for many hormonesand neurotransmitters-induced cell signals, the present findings also show the possibility that gintonin could be a novel first messenger and could utilize $\mathrm{Ca}^{2+}$ as a mediator of intracellular signaling pathways of a variety of physiological and pharmacological actions of ginseng.

\section{ACKNOWLEDGEMENTS}

This work was supported by Basic Science Research Program through the National Research Foundation of Korea funded by the Ministry of Education, Science and Technology (R01-2008-000-10448-0), Priority Research Centers Program through the National Research Foundation of Korea funded by the Ministry of Education, Science and Technology (2009-0093824), and BK21 to SY Nah.

\section{REFERENCES}

1. Nah SY. Ginseng: recent advances and trends. Korean J Ginseng Sci 1997;21:1-12.

2. Shibata S, Tanaka O, Soma K, Ando T, Iida Y, Nakamura $\mathrm{H}$. Studies on saponins and sapogenins of ginseng: the structure of panaxatriol. Tetrahedron Lett 1965;42:207213. 
3. Wagner-Jauregg T, Roth M. On panaxol, a new constituent of "red" ginseng root. Pharm Acta Helv 1962;37:352359.

4. Kanzaki T, Morisaki N, Shiina R, Saito Y. Role of transforming growth factor-beta pathway in the mechanism of wound healing by saponin from Ginseng Radix Rubra. Br J Pharmacol 1998;125:255-262.

5. Choi S, Rho SH, Jung SY, Kim SC, Park CS, Nah SY. A novel activation of $\mathrm{Ca}(2+)$-activated $\mathrm{Cl}(-)$ channel in Xenopus oocytes by Ginseng saponins: evidence for the involvement of phospholipase $\mathrm{C}$ and intracellular $\mathrm{Ca}(2+)$ mobilization. Br J Pharmacol 2001;132:641-648.

6. Choi S, Kim HJ, Ko YS, Jeong SW, Kim YI, Simonds WF, Oh JW, Nah SY. G alpha(q/11) coupled to mammalian phospholipase $\mathrm{C}$ beta 3-like enzyme mediates the ginsenoside effect on $\mathrm{Ca}(2+)$-activated $\mathrm{Cl}(-)$ current in the Xenopus oocyte. J Biol Chem 2001;276:48797-48802.

7. Lee JH, Jeong SM, Lee BH, Kim JH, Ko SR, Kim $\mathrm{SH}$, Lee SM, Nah SY. Effect of calmodulin on ginseng saponin-induced $\mathrm{Ca} 2+$-activated $\mathrm{Cl}$ - channel activation in Xenopus laevis oocytes. Arch Pharm Res 2005;28:413420.

8. Reay JL, Kennedy DO, Scholey AB. Single doses of Panax ginseng (G115) reduce blood glucose levels and improve cognitive performance during sustained mental activity. J Psychopharmacol 2005;19:357-365.

9. Wei XY, Yang JY, Wang JH, Wu CF. Anxiolytic effect of saponins from Panax quinquefolium in mice. $\mathrm{J}$ Ethnopharmacol 2007;111:613-618.

10. Eriksson TL, Svensson SP, Lundström I, Persson K, Andersson TP, Andersson RG. Panax ginseng induces anterograde transport of pigment organelles in Xenopus melanophores. J Ethnopharmacol 2008;119:17-23.

11. Lee JH, Jeong SM, Lee BH, Noh HS, Kim BK, Kim JI, Rhim H, Kim HC, Kim KM, Nah SY. Prevention of ginsenoside-induced desensitization of $\mathrm{Ca} 2+$-activated $\mathrm{Cl}$ current by microinjection of inositol hexakisphosphate in Xenopus laevis oocytes: involvement of GRK2 and betaarrestin I. J Biol Chem 2004;279:9912-9921.

12. Jeong SM, Lee JH, Kim S, Rhim H, Lee BH, Kim JH, Oh JW, Lee SM, Nah SY. Ginseng saponins induce store-operated calcium entry in Xenopus oocytes. Br J Pharmacol 2004;142:585-593.
13. Dascal N. The use of Xenopus oocytes for the study of ion channels. CRC Crit Rev Biochem 1987;22:317-387.

14. Berridge MJ, Bootman MD, Roderick HL. Calcium signalling: dynamics, homeostasis and remodelling. Nat Rev Mol Cell Biol 2003;4:517-529.

15. Yamamoto Y, Nunome T, Yamauchi R, Kato K, Sone Y. Structure of an exocellular polysaccharide of Lactobacillus helveticus TN-4, a spontaneous mutant strain of Lactobacillus helveticus TY1-2. Carbohydr Res 1995;275:319-332.

16. Laemmli UK. Cleavage of structural proteins during the assembly of the head of bacteriophage T4. Nature 1970;227:680-685.

17. Bradford MM. A rapid and sensitive method for the quantitation of microgram quantities of protein utilizing the principle of protein-dye binding. Anal Biochem 1976;72:248-254.

18. Walker JM. The protein protocols handbook. Totawa: Humana press, 1996.

19. Scott TA, Melvin EH. Determination of dextran with anthrone. Anal Chem 1953;25:1656-1660.

20. Jorgensen NK, Petersen SF, Hoffmann EK. Thrombin-, bradykinin-, and arachidonic acid-induced $\mathrm{Ca} 2+$ signaling in Ehrlich ascites tumor cells. Am J Physiol 1999;276(1 Pt 1):C26-C37.

21. Grynkiewicz G, Poenie M, Tsien RY. A new generation of $\mathrm{Ca} 2+$ indicators with greatly improved fluorescence properties. J Biol Chem 1985;260:3440-3450.

22. Dobrydneva Y, Blackmore P. 2-Aminoethoxydiphenyl borate directly inhibits store-operated calcium entry channels in human platelets. Mol Pharmacol 2001;60:541-552.

23. Yoon JY, Ha BH, Woo JS, Lim YH, Kim KH. Purification and characterization of a $28-\mathrm{kDa}$ major protein from ginseng root. Comp Biochem Physiol B Biochem Mol Biol 2002;132:551-557.

24. Abdrasilov BS, Kim YuA, Nurieva RI, Dedkova EN, Leonteva GA, Park HJ, Zinchenko VP. The effect of total saponins from Panax ginseng C. A. Meyer on the intracellular signalling system in Ehrlich ascites tumor cells. Biochem Mol Biol Int 1996;38:519-526.

25. Choi S, Lee JH, Kim YI, Kang MJ, Rhim H, Lee SM, Nah SY. Effects of ginsenoside on G protein-coupled inwardly rectifying $\mathrm{K}^{+}$channel activity expressed in Xenopus oocytes. Eur J Pharmacol 2003;468:83-92. 